\title{
Correlates of Attempts to Quit Smoking: A Hierarchical Multiple Linear Regression Analysis
}

Siddiq M, Rahman MM, Gahamat MF

Faculty of Medicine and Health Sciences, Universiti Malaysia Sarawak

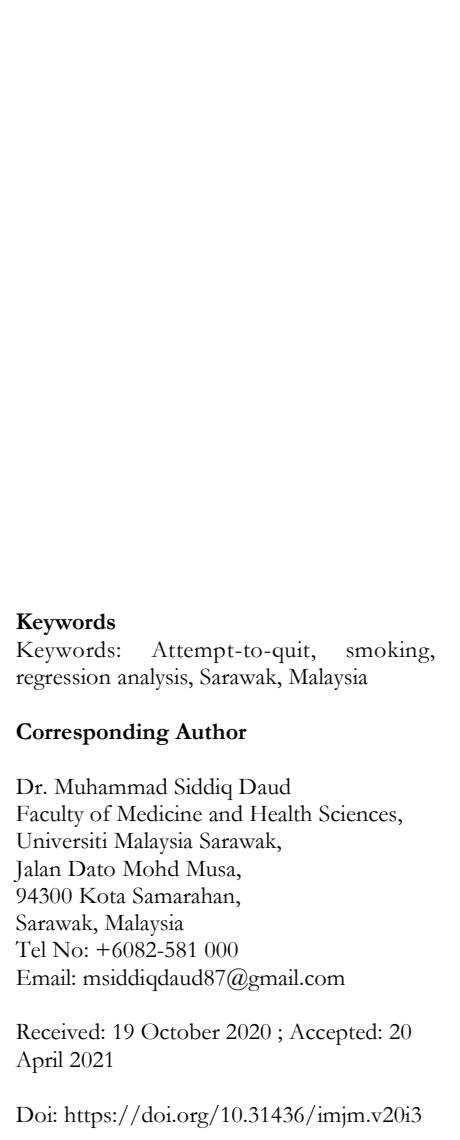

\begin{abstract}
Background: Smoking is a public health concern that contributes to non-communicable disease fatalities. Nearly five million Malaysians aged 15 years and above are estimated to be smokers. Quitting smoking is complicated and challenging for most smokers to attempt and succeed. Not everyone enjoys it, but some have decided and/or tried to stop smoking completely. This study aimed at identifying predictors of quit smoking attempts. Methods: The researchers designed a cross-sectional study conducted in Samarahan Division, Sarawak, Malaysia. Data from 777 smokers were collected via face-to-face interview using a validated structured questionnaire. A hierarchical multiple regression analysis was performed to determine the factors associated with quit smoking attempts by IBM SPSS version 22.0. A p-value of $\leq .05$ was considered statistically significant. Results: The average age of the smokers was 43.46 years old, with the male to female ratio of 8.96:1. The median age of starting and being regular smoking were 20 and 23 years, respectively. The hierarchical multiple linear regression analysis revealed that motivation $(\beta=.220, \mathrm{p}<.001)$, intention to quit $(\beta=.148, \mathrm{p}<.001)$, age at regular smoking $(\beta=.131$, $\mathrm{p}<.01)$, gender $(\beta=.088, \mathrm{p}<.01)$ appeared to be significant predictors of quit smoking attempt. Self-efficacy $(\beta=-.101, \mathrm{p}<.05)$ had a negative effect on quit smoking. However, nicotine dependency and the age of respondents did not affect smoking cessation. Conclusion: Smoking cessation motivation, intention, and age of regular smokers were associated with quit attempts. Therefore, the aim of a future campaign should be to reinforce motivation, increase the level of intention and self-esteem for successful smoking cessation.
\end{abstract}

\section{INTRODUCTION}

Tobacco consumption includes smoking and the misuse of smokeless tobacco products. The tobacco epidemic is addictive and one of the world's most severe threats to public health, killing approximately 8 million people every year. Millions of tobacco users have lung cancer, tuberculosis, asthma, or chronic lung disease. ${ }^{1}$ Tobacco killed 3.3 million smokers in 2017, while 1.5 million people suffered from chronic respiratory diseases due to second-hand smoking, including; 1.2 million deaths from cancer (tracheal, bronchus, and lung) and 600,000 deaths from respiratory infections and tuberculosis. ${ }^{1}$

In 2019, 4.8 million Malaysians over the age of 15 smoked cigarettes, with 40.5 percent of males and 1.2 percent of female smokers. ${ }^{2}$ It was found that the male smoker prevalence decreased from $43.0 \%$ in 2015 to
$40.5 \%$. In contrast, the prevalence among females decreased significantly from $1.4 \%$ in 2015 to $1.2 \% .^{2}$ Malaysia will reduce the national smoking prevalence by 30\% from the 2011 baseline (WHO Global NCD Target 2025) by decreasing adolescent smoking initiation and supporting current smokers to overcome nicotine dependence. ${ }^{3}$ The government has invested 2.92 billion MYR in reducing half of the current smoking rate by the year 2020 and in increasing the year of life lost (YLL) and disability-adjusted life-year (DALY) attributed to smoking-related diseases. ${ }^{4}$

Smoking is associated with multiple diseases and has adverse consequences. ${ }^{4-6}$ Quit smoking hinders smoking -related illnesses and deaths. ${ }^{7}$ Thus, motivation in the cessation of smoking has been the subject of tobacco 
studies for the last 25 years. ${ }^{5}$ There is a relationship between motivation and quitting smoking. Theories about smoking cessation are attributed to motivation, which is a prerequisite for a quit attempt. ${ }^{8}$ Therefore, recognising the smokers' former and current motivation levels in terms of quitting smoking is crucial. ${ }^{9}$ Most smokers were heavily motivated and driven to quit smoking due to health concerns about tobacco-related diseases; many of them accomplished it effectively. ${ }^{10}$ Nevertheless, smokers decided to boost their health and alleviate smoking-related afflictions. Another factor that motivates smokers to quit was potential illness apprehension, although their bodies at the moment have shown no symptoms of diseases attributable to any affliction. ${ }^{5}$ Smokers with positive intentions were more likely to quit smoking successfully. Developing smoking cessation interventions for motivated quitters is beneficial as compared to less-driven ones. The Transtheoretical Model (T'TM) and its component, The Stages of Change (SOC), developed by Prochaska et al. (1992), was the best model when it comes to smoking cessation motivation. ${ }^{8}$

Smoking cessation self-efficacy is the most critical smoking abstinence factor, especially for smokers who initiate a quit attempt. ${ }^{11}$ Several studies have found that smokers' self-efficacy attempting to quit smoking affected smoking cessation and interventions; it aided in long-term smoking reductions. ${ }^{12-14}$ If the attitude and subjective norms are favourable, smokers would be motivated to quit smoking with greater perceived behavioral control. However, it needs a firm intention and motivation. ${ }^{15}$ Most of the research encouraged healthcare workers to understand the importance of motivation and self-efficacy on quit-smoking intention and the attempts to enhance smoking-cessation interventions. ${ }^{16}$ This study examined motivation, selfefficacy, and nicotine dependence as predictors of smoking cessation attempts among smokers.

\section{METHODS}

\section{The setting, population, and sampling}

The researchers conducted a cross-sectional community -based study. Smokers aged 18 years and above, irrespective of gender, living in Samarahan and Asajaya Districts of Sarawak were included as samples. Smokers IMJM Volume 20 No.3, July 2021 were defined as individuals who smoked at least one cigarette a week. ${ }^{17}$ Subjects with pre-existing mental disease or cognitive impairment were excluded. The study was conducted from January 2019 until May 2019. A multistage cluster sampling technique was followed to select the participants. The calculated sample size was 806 , with the base prevalence of attempt to quit was $28 \%$ among the rural smoker ${ }^{18}$ with $30 \%$ attrition and $5 \%$ precision. The two districts are comprised of 99 villages. The systematic random sampling method starting from the Penghulu's house (Cluster headman) was preceded by the $n^{\text {th }}$ interval of the house on the left, right, the front, and the back of the house. The process continued according to the inclusion criteria. If the selected $n^{\text {th }}$ interval house was vacant or satisfied exclusion criteria, the researcher chose a house next to it and continued the process.

\section{Data collection instruments}

The researchers collected data via face-to-face interviews utilising a structured questionnaire. The questionnaire consisted of demographic characteristics, nicotine dependence level, motivation level to quit smoking, self-efficacy in quitting smoking, level of intention, and quitting smoking attempt sections. The initial questionnaire was written in the English language. It was validated and back-to-back translated into Bahasa Melayu by two different high proficiency professionals in English and Bahasa Melayu. A pre-test was carried out in the non-sample area to determine the proposed analysis viability by assessing the respondent's comprehension of the questionnaire, questionnaire efficiency, and methodology feasibility and practicality.

\section{MEASURES}

\section{Dependent variable}

Quit smoking attempts: The researchers measured it using two-item questions such as 'ever attempted to quit smoking' and 'attempted to quit smoking in the last 12 months'. The response categorised as 'never tried to quit' (0 score), 'once' (1 score), '2-3 times' (2 scores), and 'more than three times' (3 scores). A summative score was calculated as a continuous variable considered as a dependent variable. 


\section{Independent variables}

The first independent variable was 'Level of self-efficacy', measured based on the smoking Abstinence SelfEfficacy Questionnaire (SASEQ). A high score meant a higher level of self-efficacy in smoking cessation. The SASEQ scale range was between 0 and $24 .{ }^{19}$

The second independent variable was Level of nicotine dependence' was assessed by the Fagerström Test for Nicotine Dependence (FTND). ${ }^{3}$ Same as self-efficacy, a high score indicates nicotine dependency.

The third independent variable was Level of motivation and stage of change', measured by adopting the Transtheoretical Model (TTM) version. ${ }^{20}$ It was a stage of transition, decided by the respondents. The TTM posits that individuals move through six stages of change: precontemplation, contemplation, preparation, action, and maintenance. ${ }^{21}$

The fourth independent variable was 'The intention to quit smoking. The questions adapted from a study done in the USA in 2009 were used to recognise the purpose of quitting smoking and the intention to seek support in smoking cessation within the next three months.22,23

The 'socio-demographic characteristics' include variables of age, marital status, ethnicity, religion, type of occupation, level of education, as well as smoking status, number of smokers in the family, and monthly income.

\section{Data Entry and Analysis}

The data obtained were examined and number-coded for integration into Microsoft Office Excel 365 (Microsoft Corporation and IBM SPSS version 22). ${ }^{24}$ The data were reviewed for misinterpretation, inconsistencies, or repetition. The results were presented in tables of frequency, mean, minimum, maximum, median, and standard deviation. A hierarchical multiple linear regression analysis was performed to determine the factors associated with attempt-to-quit smoking (continuous quantitative variable). The quit smoking attempt was a dependent variable with continuous data. Gender was a dummy, coded ' 1 ' (male) and ' 0 ' (female). The other variables joined the model as continuous variables. Two factors, initially viz. age and gender, were applied to the model, preceded by other factors such as the age when becoming regular smokers and dependency on nicotine. Afterward, self-efficacy, motivation phase, and quit-smoking intention were entered and became part of the model. An exploratory data analysis was performed to determine potential outliers and skewed data before multivariate analysis. Univariate and multivariate outliers were determined using Mahalanobis distance, ${ }^{25}$ with a $\mathrm{p}$-value of $\leq 0.05$ and studentized residual at 95\% confidence interval of absolute value $\pm 2.0 .{ }^{26}$ Due to outliers, 68 data were removed. Multicollinear variables were excluded from the model after bivariate Pearson's moment correlation. The $\mathrm{p}$-value of $\leq 0.05$ was considered statistically significant.

\section{Ethical considerations}

The researchers obtained ethics approval from the Ethics Committee of Universiti Malaysia Sarawak. All participants were briefed, and their written informed consent was obtained as verification. District offices and local councils permitted data collection in their respective localities.

\section{RESULTS}

\section{Characteristics of the smokers}

Table I illustrates the socio-demographic profile of smokers. Most $(90 \%)$ of them were males. The average (SD) age was $43.46(14.81)$ years. The highest percentage were Malay $(77.6 \%)$, followed by Iban (10.8\%), Chinese $(10.7 \%)$, and the least respondents were Bidayuh $(0.9 \%)$. The mean (SD) family income was MYR 1835.94 (862.37) with a minimum of MYR 300 and a maximum of MYR 5000. The highest percentage represented selfemployed (44.7\%), followed by private employees $(24.7 \%)$, while the lowest was retirees $(1.8 \%)$. In terms of education, $60.2 \%$ of respondents completed the secondary level.

The mean (SD) age of starting smoking was 20.9 (4.7), in which 12 years old was the minimum age of starting smoking. The median (SD) age of a regular smoker was 23.28 (5.32) years. The mean time interval (SD) between regular smoking and onset of smoking was 2.37 years 
(2.27). Table II shows the median number of family members who smoke are 2 , with at least 1 individual and a maximum of 7 people being smokers.

Table I Characteristics of the smokers

\begin{tabular}{ll}
\hline Characteristics & \multicolumn{2}{l}{ Frequency } \\
\cline { 2 - 2 } & $\mathbf{n} \quad \mathbf{( \% )}$ \\
\hline Age of smoker (years) & $43.46(14.81)^{*}$
\end{tabular}

Gender

$\begin{array}{lll}\text { Male } & 699 & (90.0) \\ \text { Female } & 78 & (10.0)\end{array}$

Marital status

$\begin{array}{lll}\text { Single } & 177 & (22.8) \\ \text { Married } & 577 & (74.3) \\ \text { Divorced } & 13 & (1.7) \\ \text { Widow/Widower } & 10 & (1.3)\end{array}$

Ethnicity

$\begin{array}{lll}\text { Malay } & 603 & (77.6) \\ \text { Chinese } & 83 & (10.7) \\ \text { Iban } & 84 & (10.8) \\ \text { Bidayuh } & 7 & (0.9)\end{array}$

Religion

$\begin{array}{lll}\text { Islam } & 602 & (77.5) \\ \text { Christian } & 117 & (15.1) \\ \text { Buddhist } & 58 & (7.5) \\ \text { income (MYR) } & 1835.94(862.37) * \\ & 1700^{* *}\end{array}$

\section{Occupation}

$\begin{array}{lll}\text { Self-employed } & 347 & (44.7) \\ \text { Private employee } & 192 & (24.7) \\ \text { Government employee } & 75 & (9.7) \\ \text { Retiree } & 14 & (1.8) \\ \text { Unemployed } & 42 & (5.4) \\ \text { Student } & 24 & (3.1) \\ \text { Others*** } & 83 & (10.7)\end{array}$

Level of education

$\begin{array}{lll}\text { No formal education } & 5 & (0.6) \\ \text { Primary school } & 198 & (25.5) \\ \text { Secondary school } & 468 & (60.2) \\ \text { Diploma } & 77 & (9.9) \\ \text { Bachelor's degree } & 24 & (3.1) \\ \text { Master's degree and above } & 5 & (0.6)\end{array}$

Attempt to quit smoking: A bierarchical multiple linear regression analysis

The age and gender in the first model had potential impacts on an attempt to quit smoking with adjusted Rsquare $=0.19$. The ANOVA was statistically significant for the first model $[\mathrm{F}(\mathrm{df})=7.702(2,706) ; \mathrm{p}<0.001)]$.
Table II Descriptive statistics of smoking-related variables

\begin{tabular}{lcccc}
\hline \multicolumn{1}{c}{ Characteristics } & Median & Mean (SD) & Min & Max \\
\hline Age of starting smoking & 20 & $20.9(4.70)$ & 12 & 42 \\
$\begin{array}{l}\text { Age of regular smoking } \\
\begin{array}{l}\text { The time interval between } \\
\text { regular and first initiation of } \\
\text { smoking }\end{array}\end{array}$ & 23 & $23.28(5.32)$ & 12 & 45 \\
\begin{tabular}{l} 
Smoking family member \\
\hline
\end{tabular} & 2 & $2.37(2.27)$ & 0 & 15 \\
\hline
\end{tabular}

The second model also had potential impacts on an attempt to quit smoking with a value of adjusted Rsquare $=0.028$ for age, gender, age of becoming a regular smoker, and nicotine dependency. The ANOVA result was statistically significant $[\mathrm{F}(\mathrm{df})=6.032(2,704)$; $\mathrm{p}<0.001]$ for the second model. The second model was significantly improved at $0.9 \%$ for the adjusted R-square 0.028. Nonetheless, after variable incorporation, such as regular-smoking age, self-efficacy, nicotine dependence, motivation phase, and intention to quit smoking, the model significantly improved with adjusted R-square 0.140 , i.e., the model improved by $12.1 \%$ ( $\mathrm{p}<0.001)$. The ANOVA table of the third model was statistically significant $[\mathrm{F}(\mathrm{df})=17.478$ (7,701); $\mathrm{p}<0.001)]$. Although gender was found to be a statistically significant variable in the first model, as shown in Table III, it had a minimal impact on the third model with a contribution of $9 \%$. The analysis revealed that the quit-smoking motivation phase $(18.4 \%$ contribution) was the most critical predictor of quit, followed by quit intention $(12.5 \%$ contribution) and age of becoming a regular smoker $(10.8 \%$ contribution), which appeared to be strong predictors of quit smoking attempt $(p<0.001)$. Self-efficacy had a minimum impact on quit smoking attempt $(\mathrm{p}<0.01)$. However, nicotine dependency and the respondent's age did not influence the quit smoking attempt $(\mathrm{p}>0.05)$.

\section{DISCUSSION}

The study found that the main factor impacting quit smoking attempts was motivation, with an $18.4 \%$ contribution to the model analysis. After experiencing unpleasant health issues, smokers were mostly driven to stop the unhealthy smoking habit. This urges more research to establish if encouragement and motivation will help sustain the cessation of smoking. ${ }^{10}$ This study found that intention led to the quit smoking attempt, which contributed $12.5 \%$ to the model analysis. To be successful, smokers initially need to get a clear picture of 
Table III Attempt-to-quit smoking: A hierarchical multiple linear regression analysis

\begin{tabular}{|c|c|c|c|c|c|c|c|}
\hline \multirow{2}{*}{$\begin{array}{c}\text { Model/ } \\
\text { Variables }\end{array}$} & \multirow{2}{*}{ Unstd. B } & \multirow{2}{*}{ Std. Error } & \multirow{2}{*}{ Std.Beta } & \multicolumn{2}{|c|}{$95 \%$ CI for B } & \multirow{2}{*}{ Contribution } & \multirow{2}{*}{ Adj. $\mathbf{R}^{2}$} \\
\hline & & & & LL & UL & & \\
\hline \multicolumn{8}{|l|}{$\overline{\text { Model } 1}$} \\
\hline (Constant) & 1.712 & 0.118 & & 1.481 & 1.943 & & \multirow{3}{*}{$\begin{array}{c}0.019 \\
(p<0.001)\end{array}$} \\
\hline Age & 0.003 & 0.002 & 0.062 & -0.001 & 0.007 & 0.061 & \\
\hline Gender & 0.34 & 0.104 & $0.123^{* * *}$ & 0.135 & 0.545 & 0.121 & \\
\hline \multicolumn{8}{|l|}{ Model 2} \\
\hline (Constant) & 1.638 & 0.168 & & 1.308 & 1.968 & & \multirow{5}{*}{$\begin{array}{c}0.028 \\
(p<0.014)\end{array}$} \\
\hline Age & 0.001 & 0.002 & 0.021 & -0.003 & 0.005 & 0.018 & \\
\hline Gender & 0.347 & 0.104 & $0.125^{* * *}$ & 0.143 & 0.552 & 0.123 & \\
\hline Age (regular smoking) & 0.012 & 0.006 & 0.081 & -0.001 & 0.024 & 0.069 & \\
\hline Nicotine dependence & -0.027 & 0.012 & $-0.081 *$ & -0.051 & -0.003 & -0.08 & \\
\hline \multicolumn{8}{|l|}{ Model 3} \\
\hline (Constant) & 0.49 & 0.228 & & 0.042 & 0.938 & & \multirow{8}{*}{$\begin{array}{c}0.140 \\
(p<0.001)\end{array}$} \\
\hline Age & 0.002 & 0.002 & 0.042 & -0.002 & 0.006 & 0.035 & \\
\hline Gender & 0.243 & 0.099 & $0.088^{* *}$ & 0.049 & 0.436 & 0.086 & \\
\hline Age (regular smoking) & 0.019 & 0.006 & $0.131^{* *}$ & 0.007 & 0.031 & 0.108 & \\
\hline Nicotine dependence & 0.015 & 0.012 & 0.044 & -0.01 & 0.039 & 0.041 & \\
\hline Self-efficacy & -0.023 & 0.009 & $-0.101 *$ & -0.041 & -0.005 & -0.087 & \\
\hline Motivation phase & 0.209 & 0.04 & $0.22 * * *$ & 0.132 & 0.287 & 0.184 & \\
\hline Quit intention & 0.046 & 0.013 & $0.148^{* * *}$ & 0.021 & 0.071 & 0.125 & \\
\hline
\end{tabular}

$* \mathrm{p}<.05, * * \mathrm{p}<.01, * * * \mathrm{p}<.001$

$\mathrm{LL}=$ Lower limit, $\mathrm{UL}=\mathrm{Upper}$ limit

their desire to quit smoking. ${ }^{27}$ The intention to quit smoking, on the other hand, is influenced by the behaviour of the smokers towards smoking cessation and the perceived subjective or social norms around it. As a rule of thumb, higher intention to quit smoking causing smokers to have a more optimistic mindset and subjective norms along with higher perceived behavioural control thus will lead to the more significant individual's motivation to conduct the quit smoking behaviour. ${ }^{15,28,29}$

The study found that age of regular smoking appeared to be a predictor of quit smoking attempt, which contributed $10.8 \%$ to the model. Compared to individuals who smoke regularly at a younger age, those who smoke regularly at an older age make extra efforts to stop smoking. This might be due to the fact that adolescent's brain is more responsive to nicotine and may develop nicotine dependency even at a minimal intake. Earlier exposure to nicotine would also result in a lower incidence of quit smoking attempts. ${ }^{30,31}$ The positive correlation might be clarified by assuming that smokers tried to stop smoking due to health consequences and motivational factors. West also argued that immediate concerns about quitting smoking were due to brief advice from health professionals. ${ }^{10}$

Gender, though, played an essential role in quit smoking attempts at $9 \%$. The success rate in men was unpredictably higher than in women. The justification may be that women perceive smoking as a tool or a mechanism for coping with stress and boosting their mood. ${ }^{32}$ It is well understood that women smoke for various reasons compared to men, such as minimising harmful states (despair, anxiety, etc.), and that after they quit smoking, they experience different problems, such as weight management and the occurrence of depressive symptoms. It has also been proposed that smoking behaviour in women may be more affected than in men by behavioural components and less by nicotine dependency. ${ }^{32}$ The study found that strongly nicotine-reliant respondents, although the association was negligible, were more likely to quit smoking, vice versa. This may be attributed to subjective and nonspecific nicotine withdrawal symptoms, among others irritability, nausea, diminished concentration, excessive 
appetite, restlessness, exhaustion, and insomnia. ${ }^{33}$ In addition to the withdrawal of nicotine, smokers more likely to relapse smoking following abstinence because of the more robust societal standards, situational cognition, and a higher degree of tension felt, rather than physical reactions due to nicotine withdrawal. 34,35

Our analysis identified self-efficacy as having a negative correlation with the quit smoking attempt. This observation was consistent with Gwaltney et al. that smokers with high self-efficacy would diminish their effort to quit smoking. ${ }^{13}$ They might assume that they could quit smoking if they were genuinely willing to do so. Consequently, the higher their selfefficacy, the less critical they can perceive about smoking risks. They had little chance of quitting smoking compared to smokers who understood the risk. ${ }^{36}$ High self-efficacy or overconfidence may lead a person to ignore their possible vulnerabilities, making them more likely to relapse. In the domain of smoking behaviour, overconfidence would substantially hinder quit smoking attempts. ${ }^{37}$ Despite this, a few research has discovered that self-efficacy is one of the most significant predictors of smoking cessation and that elevated self-efficacy increases smoking cessation. 38,39 By means of motivational, cognitive, and preference mechanisms, self-efficacy beliefs help accomplish desirable modifications. In nicotine consumers trying to stop, selfefficacy plays a vital role as a mediator in cognitive behavioural improvement. 40

\section{LIMITATION}

The researchers adopted a robust data collection procedure through face-to-face interviews to obtain a large sample size. The procedure came with some limitations; a negative response such as fabricated answers and a tendency to make a false statement regarding quit smoking, especially when they realised that the researchers had a medical background. Besides, the questionnaires can be inaccurate due to misinterpretation and memory ambiguity or deficiency in older respondents. In order to reduce the constraint, the analysis team members presented at the field to support the respondent during the sample during the data collection session. This is especially true as these factors might prevent smokers from accurately recalling quit attempt frequencies or other details throughout their lifetime.

\section{CONCLUSION}

The analysis identified several key variables that influenced quit smoking attempts, such as gender, age at starting

IMJM Volume 20 No.3, July 2021 smoking, motivation, and self-efficacy. The study found that self-efficacy had a reverse effect on smoking cessation. Individuals in the contemplation phase had a higher attempt level to quit, followed by intention and the age of regular smoking onset. Nicotine dependency and age, however, did not have a significant effect on smoking cessation attempts. High aspiration is more likely to cater to quitting smoking. Health care providers should develop strategies such as providing more comprehensive counseling, including health, self-esteem, and reinforcing motivation to increase the quit smoking intention level, leading to successful smoking cessation.

\section{ACKNOWLEDGEMENTS}

The authors would like to thank the UNIMAS Medical Ethics Committee for their ethical approval. The authors are, therefore, indebted to various local district offices and councils for who involved and permitted the research in their areas.

\section{CONFLICT OF INTEREST}

All authors declare that there is no competing interest associated with this research.

\section{FUNDING}

Self-funded

\section{AUTHOR'S CONTRIBUTION}

MSD and MMR deliberated the study; MSD was responsible for data collection, and MMR re-analysed the data. MSD and MMR drafted the paper. All authors read and finalised the manuscript.

\section{REFERENCES}

1. WHO. WHO highlights huge scale of tobacco-related lung disease deaths. [online]. Available at: https:// www.who.int/news-room/detail/29-05-2019-whohighlights-huge-scale-of-tobacco-related-lung-diseasedeaths.Accessed May 3, 2020.

2. Institute for Public Health (IPH). National Health and Morbidity Survey (NHMS) 2019: Vol. I: NCDs - NonCommunicable Diseases: Risk Factors and Other Health Problems. National Institutes of Health, Ministry of Health Malaysia; 2020.

3. Ministry of Health Malaysia. Clinical practice guidelines on treatment of tobacco use disorder. [online] 2016.

4. Lim HK, Ghazali SM, Kee CC, et al. Epidemiology of smoking among Malaysian adult males: prevalence and associated factors. BMC Public Health. 2013;13:8. 
5. Buczkowski K, Marcinowicz L, Czachowski S, Piszczek E. Motivations toward smoking cessation, reasons for relapse, and modes of quitting: results from a qualitative study among former and current smokers. Patient Prefer Adherence. 2014;8:1353-1363.

6. Saha SP, Bhalla DK, Whayne TF, Gairola C. Cigarette smoke and adverse health effects: An overview of research trends and future needs. Int J Angiol Off Publ Int Coll Angiol Inc. 2007;16(3):77-83.

7. U.S. Department of Health and Human Services. Smoking Cessation. A Report of the Surgeon General. Centers for Disease Control and Prevention, National Center for Chronic Disease Prevention and Health Promotion; 2020:700.

8. Herzog T, Pokhrel P, Kawamoto CT. Short-term fluctuations in motivation to quit smoking in a sample of smokers in Hawaii. Subst Use Misuse. 2015;50(2):236 $-241$.

9. Roberts NJ, Kerr SM, Smith SMS. Behavioral Interventions Associated with Smoking Cessation in the Treatment of Tobacco Use. Health Serv Insights. 2013;6:79.

10. West R. Tobacco smoking: Health impact, prevalence, correlates and interventions. Psychol Health. 2017;32 (8):1018-1036.

11. Berg CJ, Cox LS, Mahnken JD, Greiner KA, Ellerbeck EF. Autonomous Motivation as a Critical Factor in SelfEfficacy among Rural Smokers. J Health Psychol. 2008;13(3):416.

12. Blevins CE, Farris SG, Brown RA, Strong DR, Abrantes AM. The Role of Self-Efficacy, Adaptive Coping, and Smoking Urges in Long-term Cessation Outcomes: Addict Disord Their Treat. 2016;15(4):183-189.

13. Gwaltney CJ, Metrik J, Kahler CW, Shiffman S. SelfEfficacy and Smoking Cessation: A Meta-Analysis. Psychol Addict Behav J Soc Psychol Addict Behav. 2009;23(1):56-66.

14. Lee YY, Khoo S, Morris T, et al. A mixed-method study of the efficacy of physical activity consultation as an adjunct to standard smoking cessation treatment among male smokers in Malaysia. SpringerPlus. 2016;5(1).

15. Droomers M, Huang X, Fu W, Yang Y, Li H, Zheng P. Educational disparities in the intention to quit smoking among male smokers in China: a cross-sectional survey on the explanations provided by the theory of planned behaviour. BMJ Open. 2016;6(10):e011058.

16. Hughes J, Naud S. Perceived role of motivation and self -efficacy in smoking cessation: A secondary data analysis. Addict Behav. 2016;61.

17. Lim K, Teh C, Lim L, et al. Smoking among Secondary School Students in Kota Tinggi, Johor, Malaysia-Findings from a Cross-Sectional Study. Asian Pac J
Cancer Prev APJCP. 2015;16:4563-4570.

18. IPH, Malaysia. National Health and Morbidity Survey 2015 (NHMS 2015). Vol. II: Non-Communicable Diseases, Risk Factors \& Other Health Problems. Institute for Public Health (IPH), Ministry of Health Malaysia [online]. 2015:315. Available at: https:// www.moh.gov.my/moh/resources/ nhmsreport2015vol2.pdf

19. Spek V, Lemmens F, Chatrou M, van Kempen S, Pouwer F, Pop V. Development of a smoking abstinence self-efficacy questionnaire. Int J Behav Med. 2013;20(3):444-449.

20. Stockings E, Bowman J, McElwaine K, et al. Readiness to quit smoking and quit attempts among Australian mental health inpatients. Nicotine Tob Res. 2013;15 (5):942-949.

21. Fidanc1 İ, Ozturk O, Unal M. Transtheoretic model in smoking cessation. J Exp Clin Med Turk. 2017;34.

22. Wong NCH, Cappella JN. Antismoking threat and efficacy appeals: Effects on smoking cessation intentions for smokers with low and high readiness to quit. J Appl Commun Res JACR. 2009;37(1):1-20.

23. Ying WK, Rahman M. Factors Determining Attempt-toQuit Smoking among Adult Current Smokers in Sarikei, Sarawak, Malaysia. Malays J Public Health Med. 2017;17 (2):96-102.

24. IBM SPSS. IBM SPSS Statistics for Windows. IBM SPSS; 2013.

25. Sharma A. Understanding Mahalanobis Distance And Its Use Cases. Analytics India Magazine [online]. Available at 19. https://www.analyticsindiamag .com/ understanding-mahalanobis-distance-and-its-use-cases. Accessed June 10, 2019.

26. Gray JB, Woodall WH. The Maximum Size of Standardized and Internally Studentized Residuals in Regression Analysis. Am Stat. 1994;48(2):111-113.

27. Hughes JR. Motivating and Helping Smokers to Stop Smoking. J Gen Intern Med. 2003;18(12):1053-1057.

28. Alanazi NH, Lee JW, Dos Santos H, Job JS, Bahjri K. The use of planned behavior theory in predicting cigarette smoking among Waterpipe smokers. Tob Induc Dis. 2017;15(1):29.

29. Hosking W, Borland R, Yong H-H, et al. The effects of smoking norms and attitudes on quitting intentions in Malaysia, Thailand, and four Western nations: A crosscultural comparison. Psychol Health. 2009;24(1):95-107.

30. Ali FRM, Agaku IT, Sharapova SR, Reimels EA, Homa DM. Onset of Regular Smoking Before Age 21 and Subsequent Nicotine Dependence and Cessation Behavior Among US Adult Smokers. Prev Chronic Dis. 2020;17(E06):1-6.

31. Goriounova NA, Mansvelder HD. Short- and Long- 
Term Consequences of Nicotine Exposure during Adolescence for Prefrontal Cortex Neuronal Network Function. Cold Spring Harb Perspect Med. 2012;2(12):114.

32. Marqueta A, Nerín I, Gargallo P, Beamonte A. Gender differences in success at quitting smoking: Short- and long-term outcomes. Adicciones. 2016;29(1):13-21.

33. Suh G. Addictiveness of tobacco and smoker's ability to quit smoking. Seoul Law Firm Shin Kim. Published online 2016:4-23.

34. Roh S. Scientific Evidence for the Addictiveness of Tobacco and Smoking Cessation in Tobacco Litigation. J Prev Med Pub Health. 2018;51(1):1-5.

35. Põld M, Pärna K. Nicotine Dependence and Factors Related to Smoking Cessation among Physicians in Estonia. Int J Environ Res Public Health. 2020;17(9).

36. Poggiolini C. High self-efficacy regarding smoking cessation may weaken the intention to quit smoking. Cogent Psychol. 2019;6(1):1574096.

37. Scheiding RA. Smoking cessation and self-efficacy [online] Available at: https://etd.ohiolink.edu/! etd.send_file? accession $=$ marietta $1260369637 \&$ disposition $=$ inline

38. Blevins CE, Farris SG, Brown RA, Strong DR, Abrantes AM. The role of self-efficacy, adaptive coping, and smoking urges in long-term cessation outcomes: Addict Disord Their Treat. 2016;15(4):183-189.

39. Wee L, Chan C, Yogarabindranath S. A review of smoking research In Malaysia. Med J Malaysia. 2016;71 (Suppl 1).

40. Elshatarat RA, Yacoub MI, Khraim FM, Saleh ZT, Afaneh TR. Self-efficacy in treating tobacco use: A review article. Proc Singap Healthc. 2016;25(4):243-248. 